\title{
Different Views? \\ The Experiences of International Students Studying HE in Three Non-university Settings
}

\author{
By Madeleine King ${ }^{*}$, Maxine Courtier ${ }^{*}$, Chet Shaw ${ }^{*}$, \\ Cynthia Anderson ${ }^{\S} \&$ John Widdowson
}

\begin{abstract}
The purpose of the research was to discover the views of three groups of International students who were undertaking their Higher Education (HE) in a publicly-funded college, rather than a university setting. A comparative survey was undertaken by International students attending an American Community College, an Australian Technical and Further Education Institute and a group of English colleges which offer Higher Education. All three groups were satisfied with their provision. The college setting was perceived to offer higher levels of support than would have been available at a university, plus enhanced employability prospects and lower fees than those charged by a university. The status of an Australian, English or American HE qualification was important, as was the reputation of their particular college. The market for International students is highly competitive and largely driven by universities. The English experience suggests that colleges should focus on the marketing of specialist courses. In all cases, the fact that teaching staff were primarily teachers, rather than researchers was highly valued by respondents, as was their currency in their subject. However, there were strong feelings about value for money and the ability to engage with Home students and wider Australian, British or American culture. International students choose to study abroad because they want to broaden their own horizons and learn more about other cultures: many respondents found these opportunities to be limited. In order to help address this, an International student recruitment Checklist for senior college staff is presented as part of the research findings.
\end{abstract}

Keywords: Higher Education, International students, colleges, value-for-money.

\section{Introduction}

Much has been written about International students and universities, with comparatively little attention (in England, at least) paid to those who choose to pursue their Higher Education (HE) in a college setting. This paper is about some of those college-based students. It reports the findings of a survey carried out in 2017-18 into the views of International students who are studying for HE qualifications in a publicly-funded college rather than a university. We set out to answer the question "Are there any lessons and successful practice to be drawn from the experiences of International students studying in non-university contexts in three English-speaking countries?"

\footnotetext{
*Research and International Officer, New College Durham, UK.

'Dean, Holmesglen Technical and Further Education Institute, Australia.

tDean, Moraine Valley Community College, USA.

${ }^{\S}$ Dean, Moraine Valley Community College, USA.

'Principal and Chief Executive, New College Durham, UK.
} 
The research involved students enrolled in three locations - Holmesglen Technical and Further Education Institute (TAFE) in Melbourne, Australia, Moraine Valley Community College near Chicago, in the United States and members of the Mixed Economy Group of English Further Education (FE) colleges. With some local adjustments to reflect use of language and academic terminology within the three countries, the same survey questionnaire was used with all three groups of students, making it possible to compare the responses to particular issues. The Mixed Economy Group (MEG) had carried out a similar survey of International students within its member colleges in 2013.

The survey set out to compare responses to a number of areas of student life. These included accommodation; sources of course funding; teaching and learning issues; social integration; motivation to study in Australia, England or the US, whether or not the student felt welcome in the country/on campus and their overall views on the value for money offered by their institution. We focus our paper on these last four issues. They were the subject of much discussion at national level in each country at the time of the survey, and continue to be so at the time of writing. The responses to the section on teaching and learning are referred to in less detail. This is not to undervalue them: teaching and learning formed a large component of the survey and is better served by being the subject of a separate document.

Our paper is set out in eight sections. Section 2 offers an overall context for our work, section 3 looks at previous research into the same area and as a precursor to our results we describe the three separate college contexts in section 4 . Section 5 looks at the methodology and 6 gives the results of the three surveys, the significance of which we discuss in section 7. Our final section offers a commentary and suggested way forward for colleges. The research output includes a practical Checklist for college leaders and senior managers. Alongside this primary research we also comment on the impact of national policies on local college experiences.

\section{Survey Context}

Considerable change has taken place in the English HE political and educational landscape since the MEG carried out its first survey of International students in 2013. Whilst the spectre of Brexit casts a long shadow over many UK educational institutions' plans for internationalisation, these are made worse by the UK Government's long-standing commitment to a reduction in immigration numbers. Despite much debate, International students are included in these figures. Whatever the political rights and wrongs of these matters, there is a general sense amongst prospective International (and European Union) students that they may not be welcome in the UK (UK Council for International Student Affairs, 2017).

A similar degree of ambivalence surrounds the actions of the American and Australian Governments. Spokesmen for both countries have repeatedly voiced their determination to exercise more control on immigration whilst actively promoting their $\mathrm{HE}$ provision to international markets. 
In all three countries International students pay considerably higher fees at university than Home students, providing valuable income to institutions which may otherwise struggle to balance their books. Within any year group of students following a particular course, some may be paying three times as much as others for identical provision. Whilst this situation is less likely to apply in a college setting (fees are higher for International students, but far less than in the university system) the surveys aimed to gauge whether these students consider their courses are value for money and whether they feel welcome in Australia, England or the USA.

During the period in which the research was conducted and in the year following, International students and their choices of $\mathrm{HE}$ provider came under increasing focus by all three Governments and their national HE institutions. The value of International students, both economic and in terms of the internationalisation of university/college campuses, had always been understood but gained increasing focus. Competition for this group of students increased significantly as Education budgets in the US, UK and Australia were cut.

In the UK evidence began to emerge that conflicting Immigration and Education policies and the implications of Brexit had led to a decline in International student numbers. Second only to the US as a venue for these students for decades, UNESCO data suggested that the UK had now been overtaken by Australia. A useful overview of the history of UK International student recruitment, including the values that shaped successive policy decisions, is to be found in Kumari (2018). This was written for the Higher Education Commission as its contribution to the swathe of debate surrounding International students and Immigration policy that took place in the UK across 2018. Similar documents appeared in Australia and the US during 2017-19, often building on concerns that had emerged a decade earlier (NAFSA, 2009; and 2019a, in the US).

In England these discussions led to a long-overdue commitment to increase International student recruitment, but with only minor changes to the existing immigration and visa constraints. At around the same time, Conlon, Halterbeck \& Hedges (2019) examined the financial contribution made by International students who graduate and then find employment in the UK. The main headline from this was that just one cohort of such graduates raised $£ 3.2$ billion in taxes. Countering another suspicion, the report was also able to prove that far from displacing Home graduates in the job market, International students typically worked in sectors suffering from acute skills shortages. Similar conclusions with regard to the economic value of their own International students were reached in the US (NAFSA, 2019b) and Australia (ICEF Monitor, 2018).

\section{Literature Review: The International Student Experience in Colleges}

Unsurprisingly, given their status as a recognised part of the American HE system, research in this area is greatest around Community Colleges. It is also far from recent. Lee \& Rice (2007) noted that host communities can be intolerant and sometimes had racist views. Vafors Fritz, Chin, \& DeMarinis (2008) concluded 
that International students were often wrongly regarded as a homogenous group. They found that some issues were more stressful to some nationalities than others and that academic staff were less sensitive to these differences than might have been assumed. Yeh \& Inose (2010) discussed acculturation stresses as did Smith \& Khawaja (2011) who again concluded that the host society had a key role in helping students to adjust to their new surroundings.

One particular piece of research provides a backdrop for our study. In a doctoral thesis published in 2017, Guyton noted that International students in rural Community Colleges sought out students from the same country for emotional and social support, especially those in higher years who were following the same course. English language support was frequently referred to, often in the context of having learnt English as a second language and, within that, British English rather than US English. Many International students found that US students were polite but not interested in socialising with them, reverting to their own longerestablished local friendship groups after class. Loneliness was a problem for the International students, made worse by a rural location.

In her conclusions, Guyton (2017) recommends that college staff actively promote social contacts in the college and in the community, including organising summer internships in order to promote employability skills amongst International students. This would also enable local businesses to benefit from their skills. She noted that the impact of different educational systems is often underestimated: in some cultures the teacher is a respected individual whose word is simply not to be challenged. In UK, US and Australian HE settings, a far greater degree of interaction is expected, which further exacerbates any lack of confidence in spoken English skills. The cultural sensitivities of teaching and non-teaching staff were perceived to be an issue. Guyton concluded that formal training in internationalisation and in different learning styles should be mandatory in any Community College that recruits from abroad. Linked to this was a conclusion that staff make too many assumptions about International students and the extent of their preparation before arriving in the country. Many students spoke about a lack of clarity over the true cost of courses, which were often far higher in practice than they had assumed from their initial research. When coupled with limited opportunities to work on campus, this led to hardship.

These findings are reflected in subsequent research and commentaries. In Australia Tran \& Dempsey (2017) authored an overview of internationalisation in vocational and educational training (VET). This noted that during the 1980s, Australia shifted its approach to teaching International students, moving from seeing education as a form of aid to one of trade. International students were subsequently regarded as revenue and Government funding to providers was reduced. The book refers to VET providers as significant but often-neglected players within the field of international education. The editors suggest that whilst many types and sizes of institutions are caught up in the drive to recruit International students, managing that process and then adapting as institutions to a new student balance requires careful consideration and planning.

Leask \& Carroll (2013) offered pragmatic advice to staff teaching International students, focusing on how to help their integration into the wider community. 
Martin (2018), writing in The Interpreter (the Lowy Institute) noted that the majority of Chinese students leave Australian universities disappointed by their social experiences. They have few local friends and are unlikely to have found meaningful work in local companies. She concluded that their time is marked by isolation and little cross-cultural engagement. Martin poses the question that since International students pay three times the fees of their domestic peers, is it unreasonable to invest some of this income in improving their social experience? As elsewhere, Chinese students in Australia consider that their Australian peers are indifferent to making friends with them. Martin suggests that young Australians want and need to develop an understanding of their Asian neighbours but somehow lack the skills to talk to students sitting in the same classroom. She concludes that this could be remedied by a systematic and informed approach to training Home students and their teachers about how to make the most of the valuable social and cultural resource sitting in their midst.

In England, little has been written about International students pursuing their $\mathrm{HE}$ in an FE college setting. This reflects both the arrangements concerning the delivery of HE in the UK (see next section) and the numbers of students involved. The attention that has been paid to International students is largely from a university perspective, but typically reflects many of the findings referred to above. Mellors-Bourne et al (2013, p. 12) offers a useful summary:

"Many host institutions and wider communities become far more multi-cultural through the presence of International students. However, whether exposure to students from other cultures manifests in greater tolerance can depend on the nature of these interactions and the degree of integration of internationally mobile students into their host communities. There is potential for a 'darker side' which can include racism or violence against International students, concerns about overrepresentation of International students on university campuses, and a lack of integration between domestic and International students."

Our research covers these same issues and seeks to see if any ways forward can be found.

\section{Setting the Scene}

In the US, the 1,103 Community Colleges are an established part of the HE world. Many students begin their undergraduate life on an Associate Degree in a local college before transferring to a university to complete their Bachelor's degree. Whilst most universities are in urban environments, Community Colleges enable those in rural locations to access technical and higher skills.

In the UK, the 257 Further Education colleges cover a similarly wide geographical area, fulfilling the same functions as their American equivalents. Unlike the US and Australia, however, a long-standing distinction exists between Further and Higher Education. Further Education offers a range of courses post-school but at a level below a US Associate Degree or English Foundation Degree or HNC/D. Until recently, only universities were able to award and 
deliver HE courses: whilst this has changed, 90\% of HE is still awarded and delivered by universities. Only two colleges have full degree-awarding powers, with seven being able to offer two-year Foundation Degrees.

In Australia, the Technical and Further Education Institutes provide opportunities for students to access a similar range of skills as their Community College and FE College counterparts but with the difference that 11 TAFEs are recognised HE providers in their own right. However, unlike the situation in the UK and US, Domestic students following HE courses in TAFEs are generally unable to draw down government-funded student loans.

All three types of college are characterised by an approach to HE that is employer/employment focused. This is often described as Higher Technical Education or Higher VET (HVET) as a means of distinguishing it from the more traditional approach of a campus university. Students are more likely to be in their mid-20s and older, are often the first in their families to experience HE and are more likely to live at home. Across all three institutions, the majority of the students in our survey were following HVET courses, such as Nursing, Accountancy, and Hotel Management.

\section{English Colleges}

The number of International students (i.e. not Home or European Union students) studying HE in an English FE college in 2015-16 was 1,190. A year later, this had dropped to 879, of whom 566 were attending MEG member colleges. These students were largely split between three MEG institutions two specialist maritime providers and an agricultural college with specialist provision in the field of equine science. By 2017-18 numbers had declined significantly. Only 667 International students were enrolled on college-based HE courses, of which 384 were attending a MEG college. As in previous years, most of these were enrolled on specialist courses (Higher Education Funding Council for England, 2017, 2018).

In parallel to the student survey, a separate survey of MEG representatives revealed that one college had no International students on roll at all, despite having been one of the biggest recruiters within the college system across the last 5 years. Of the 23 respondents to this numerical survey, only 3 colleges had more than 30 International students, and only 2 of these had more than 50. A similar pattern emerged with EU students.

In England, most International students pursue their HE in a university. As a comparison to the college figures given above, in 2016-17, 263,825 International students were studying in English universities (Higher Education Statistics Agency, 2018). Most English universities have a long tradition of recruiting International students (Mellors-Bourne et al., 2013) and have wellestablished related infrastructures as a result.

MEG members agreed that three factors limit International student recruitment to colleges in the UK. Foremost are visa restrictions, including current limitations on employment opportunities for students pre- and postgraduation; heavy reliance on overseas agents, the variable reliability of agents, 
and the increasing costs of marketing overseas compared with the anticipated return.

MEG respondents noted that the costs involved in setting up, staffing and maintaining an International Office put colleges at a disadvantage when compared to their university competitors.

Despite recent policy changes, the arrangements governing student entry to the UK remain complex. Immigration policy was rarely developed as a result of discussions across Government Departments, with the result that tensions often exist between national policies concerning Education, Business, and Health and those concerning immigration. Until this year, the UK, unlike its competitors, had never stated an intention to increase International student numbers: perversely, these are included in the country's Net Migration Target. The aim of the present Government is to reduce this to tens rather than hundreds of thousands per year (House of Commons Home Affairs Committee, 2018). Across 2018, various national bodies initiated Inquiries and produced Reports which call for the inequalities and subjective judgements which mire current policy to be abandoned. Each one concluded that an agreed cross-Department policy for determining International student numbers and their means of entry to the UK was needed urgently. As an example of the existing anomalies, International students completing a course below degree level which would lead a Home student directly onto a course of HE are unable to do this (Kumari, 2018). Instead, they are required to return home and begin the whole application process again.

Partly in response to these discussions, a new International Education Strategy was announced in 2019 (Department for Education \& Department for International Trade, 2019). This commits to a cross-Department approach to immigration and to expanding International student numbers. It makes some minor changes to length of stay post-graduation - but does not address the problem referred to above.

Most of the UK's International students are from China. Numbers from the Indian sub-continent and African countries have declined significantly in the face of current immigration policies (Kumari, 2018). As elsewhere in the world, International students are required to produce evidence of financial independence: a condition of entry is that they will make no call on the public purse and can fund their own healthcare, accommodation, etc (ibid., 2018).

International students following a course of $\mathrm{HE}$ are able to work for 20 hours a week whilst studying. On completion of their courses, they are expected to return home unless they find a graduate-level job within 6 months of completing their studies. In order to comply with visa restrictions, the job must offer a minimum salary of $£ 20,800$. Competitor countries such as Australia and the US have more flexible Post Study Work offers.

\section{Moraine Valley Community College, near Chicago, Illinois}

There is an overall decline in the numbers of new International students enrolling in Higher Education institutions in the United States (Open Doors, 2019). After a steady year-on-year rise since 2011-12, the data shows a $3.3 \%$ decrease in enrolments between 2015-16 and 2016-17and a further 6.6\% fall 
between that year and 2017-18. Just under 95,000 International students were enrolled on Community College HE programmes in 2017-18, a fall of $2 \%$ on 2016-17 (Open Doors, 2019). At the same time, many Community Colleges in the United States are also experiencing a decline in Domestic student numbers.

Many factors can prompt a decline in enrolments as it relates to International students. The political climate, such as the 2017 travel ban policy for some countries and subsequent versions of this, plus on-going rhetoric concerning immigration from within the White House, has had an impact on International student numbers (Redden, 2018). American Community Colleges now face more competition for International students, who are apprehensive about studying in the United States and therefore choosing to study in other countries. Forty nine percent of International students attend colleges in five states - California, Texas, Florida, Washington and New York (Association of American Community Colleges, 2019).

The majority of International students studying in the US are Chinese, Indian or South Korean nationals, a pattern reflected in enrolments in Illinois but not found at Moraine Valley Community College. A noticeably more diverse range of nationalities is found here, with large numbers of students coming from Jordan, India, Vietnam and Korea in fall 2018.

The college experienced record enrolments for International students during 2016-17. However, a reverse began in spring 2017 semester (see Table 1 to track the declining trends with International students.) Although some of the college's International students may have graduated or transferred to a four-year institution, anecdotal evidence suggests that financial considerations and the political climate have impacted International student enrolments.

Table 1. International Student Enrolment Moraine Valley Community College

\begin{tabular}{|l|c|c|c|c|c|}
\hline $\begin{array}{l}\text { Fall } \\
\text { 2016 }\end{array}$ & Spring 2017 & Fall 2017 & Spring 2018 & Fall 2018 & Spring 2019 \\
\hline 325 & 314 & 252 & 216 & 199 & 168 \\
\hline
\end{tabular}

Source: Moraine Valley Community College 2019.

In the United States, an F1 Visa is issued to full-time students who wish to pursue a course of study that culminates in a degree, diploma, or certificate from an institution that has been authorized by the U.S. government to accept International students. This is the most common form of student visa issued to International students in the United States. A J1 Visa is issued to students wishing to participate in exchange programmes at similarly accredited schools. The major difference between a J1 Visa and an F1 Visa is the fact that a J1 visa is issued for a limited time and the programmes do not culminate in a degree, diploma, or certificate. Also, the programmes do not have to be strictly academic in nature. This should not be confused with an M1 Visa, which is intended for students pursuing specific vocational programmes in the United States. With all three visa types, students are expected to return to their home countries after completing their course of study, although Associate Degree holders can work in their field of study for up to one year after graduation. 
Moraine Valley Community College is currently only approved to issue F1 visas to International students. Students must adhere to the basic requirements for an F1 Visa, but must also meet additional institutional requirements. In order to be issued an F1 Visa, students must provide documentation demonstrating financial eligibility for one year of study and exhibit genuine intent to pursue an academic degree. In addition to this, Moraine Valley requires that all International students have completed all secondary or high school studies. English proficiency is required for an Associate Degree programme, but it is not required for entry into the college. Students who do not meet the language requirements can matriculate into an Associate Degree programme after completing intensive English study.

\section{Holmesglen Institute, Melbourne}

Holmesglen Institute of TAFE is an integrated public education provider delivering over 530 programmes to approximately 30,000 students (from vocational college (upper secondary) to Masters level) across four campuses located in Victoria, Australia. In 2017 International students totalled 3,697, sourced from 84 countries across 5 continents.

In partnership with universities, Holmesglen began operating in the HE sector during the 1980's. Since 2004 the institute has written, accredited and reaccredited 15 undergraduate, and 4 post-graduate programmes for delivery under the Holmesglen brand. It also continues to deliver a small number of undergraduate programmes in partnership with Australian universities.

The Institute's HE programmes are developed to provide a clear pathway for students graduating from lower-level vocational studies. Recognition of prior learning is applied, which often reduces the duration of a degree by a minimum of one year. The Australian Government continues to allow 'course packaging' whereby students can package two or more programmes on one student visa as long as there is a clear progression from one programme to another (Department of Home Affairs, 2018a).

International students admitted to Holmesglen's vocational programmes generally pay a reduced fee compared to those applying for direct entry to undergraduate study. It is common for International students to package their visa to combine both vocational and HE study. Since 2008 approximately $60 \%$ of International students commencing an undergraduate programme at Holmesglen entered through a vocational pathway. However, during the last two years the number applying for direct entry to year one of the Institute's degree programmes has significantly increased, particularly in the accounting, business and hotel management disciplines.

The largest numbers of International students entering HE programmes through a packaged vocational pathway programme in 2017 came from India, Sri Lanka, Mauritius and China. The Australian Government introduced a simplified student visa framework from July 1, 2016. Overseas students now apply for a single student visa (subclass 500) regardless of their programme of study, with a single immigration risk framework applied to assess all applicants. To be granted a visa, applicants are required to satisfy a number of requirements. These include 
meeting a minimum level of English language, and evidence of sufficient funds available, (including living costs indicative of the cost of living in Australia), to cover the duration of their Australian studies.

Providing applicants satisfy the legislative requirements, the Australian Government does not place a cap on the number of student visas granted. As at 30 June, 2018, there were 486,934 student visa holders in Australia. Over one third of these were from China (23.1\%) and India (14.4\%) (Department of Home Affairs, 2018b).

International students are entitled to work a maximum of 40 hours per fortnight. These restrictions only apply when their programme is in session, thus during semester breaks unlimited hours of employment apply. (Department of Home Affairs, 2018a). Following graduation with a degree from an Australian university or approved TAFE, International students can apply for a Temporary Graduate (subclass 485) visa that allows them to live and work in Australia for up to 4 years after they finish their studies.

The Australian HE sector recorded a growth rate of $14.7 \%$ in International student enrolments between 2016 and 2017, with China (38.2\%) and India $(15.5 \%)$ contributing $53.7 \%$ of these. Statistics relevant to the 2016 calendar year released by the national regulator show a total of 2,779 International student enrolments at TAFE Institutes, of which 920 were enrolled at Holmesglen (TEQSA, 2018).

In line with the national trend, Holmesglen recorded a sharp increase in International student numbers during 2016. Although commencing student numbers declined slightly in 2017, International students still accounted for $64 \%$ of all $\mathrm{HE}$ enrolments at the Institute. The majority of these enrolments continue to be concentrated in four discipline areas, namely Nursing, Hotel Management, Business and Accounting.

\section{Methodology}

Staff at all three groups of institutions drew the attention of International students to the survey and invited them to complete it on-line. The rubric at the start of the survey explained that this was a research exercise being undertaken with students enrolled in Moraine Valley Community College in the US, Holmesglen TAFE in Australia and a group of English FE Colleges in order to find out what they thought about particular aspects of their HE experience. It was made clear that all three groups were completing the same survey at the same time and that the results would be confidential. The survey was conducted in accordance with the research ethics policies of the participating institutions.

Respondents were asked to agree or disagree with a series of statements, with the opportunity to strongly agree/disagree: a neutral option was also available in some cases. The survey was constructed to enable comments to be made at the end of some sections, thus enabling a qualitative element to enter the research.

A total of 445 International students completed the survey, which ran from October 2017 - February 2018. The questions were loaded onto SurveyMonkey 
within Moraine Valley, Holmesglen and the MEG website and the results analysed by a college-based author.

\section{The Results of the Survey}

\section{What do International Students in Chicago, Melbourne and England think of their college-based HE?}

The majority of survey respondents in all three groups were aged 18-24. Just over half were female and the majority were in year 2 of a three or four year degree programme. The students in all three groups had chosen to study abroad because they wanted to experience life outside their own countries and to improve their English language skills. For many, these two factors, alongside an American, Australian or English HE qualification, were seen as a means of improving their employability prospects.

In most cases, International students chose to study a higher vocational course in a non-university institution because they see a clear link between their chosen programme, their future career, and economic success. Most students make a personal financial investment in their American, Australian or English HE: the majority of respondents take out a personal loan or receive help from their family in order to meet tuition fees. However, students are also sensitive to fee levels and are attracted by the lower cost of college-based HE.

Overall, the survey results show that students share a number of positive views about their experience. These include the high reputational value of an American, Australian or English HE qualification and the reputation of their chosen college. Students place a high value on the teaching skills of college faculty, coupled, in the case of vocational qualifications, with an appreciation of their teachers' up-to-date industrial knowledge. High levels of learning support, often outside the classroom, are perceived to be available in a college when compared to that thought to be offered at a university. This includes easy access to impartial careers information. International students value the clarity of explanation about fees, the help provided when facing issues with visas and the support they receive with course work. These are a testament to the values associated with college-based HE in three different English speaking environments.

However, two concerns are shared across all three survey outcomes, voiced clearly in the qualitative responses within the survey. First, the importance of receiving value for money, given the large personal investment identified above. Second, International students say they feel welcome in England, Australia and the US but suggest that much more could be done by Home students to engage with them and provide a deeper experience of the host community. There was a strong feeling that institutions could do more to address these points. 


\section{The MEG Responses}

The English results are best interpreted by considering the 55 respondents as belonging to one of three groups, namely a cohort of Nigerian students attending a Nautical Science course at a specialist Maritime College, funded by their Government; a separate group of International students attending a range of colleges, courses and levels of HE, and a third, smaller group, of European Union (EU) students, again attending a number of different colleges and pursuing different courses.

Despite declining International student numbers, the survey results for English colleges indicate that specialist courses are of particular interest to this group of students. In many cases they are either not available in their home country or are not affordable.

"I chose to study at Hartpury College simply because the program I am studying is not found at any university. The biggest thing for me was finding the specific program I wanted to study (equine therapy and rehabilitation). There were no other factors (money, location, etc.) besides the fact that I wanted to specialize in equine therapy and there is no university program in my home country that provides this."

Non-university HE providers intent on International student recruitment should therefore consider whether their curriculum offer contains specialist and employment-focused programmes. FE colleges offering Maritime and Landbased specialisms have clearly succeeded in developing and marketing a niche provision. Other institutions could follow suit in areas such as the Digital or Creative fields.

A second outcome from the survey is the high regard given to college teaching staff. None of the students responding to the survey disagreed with the statement that "My teachers are knowledgeable in their subject area", with most agreeing strongly.

The second group of International students referred to above is perhaps the most representative of overseas students likely to be attending English colleges. They were funded entirely through a combination of personal savings, personal loans and/or support from their families. None attended the college providing the specialist course. They were less satisfied with the administrative arrangements in their respective colleges than this first group and more likely to prefer separate social and academic facilities for HE students, rather than share facilities with often-younger FE students. They were ambivalent about whether or not they preferred to share accommodation with people from their own country but were more likely to be interested in learning about British culture and wanting to socialise with English students. The quality of teaching and careers guidance was well-regarded although several respondents commented on the lack of contact time with tutors and the slow pace of work.

"Frequency of classes is lacking - I have had 3 hours of class a WEEK from end of October until Christmas break". 
The outcomes from the survey can be summarised as:

What were your main reasons for studying in England?

- The reputation of English HE

- The experience of living abroad

- Enhanced employability prospects.

Why did you choose to study Higher Education in a college?

- Lower fees than would be charged by a university

- A higher level of support

- Lower entry criteria than a university.

Why did you choose your particular college?

- The reputation of the college

- It offered my preferred course

$92 \%$ of respondents said that they felt welcomed in England. Overall, $78 \%$ of respondents considered that their courses represented value for money.

$85 \%$ of students agreed that the teaching style in an English college was different to home. This may go some way to explaining unfavourable comments around contact time in the responses received in the English survey. These reinforce a need to ensure that adequate time is set aside to explain mutual expectations between teachers and International students, as well as the arrangements for fee payment, options choices, pastoral care, etc. All students (Home and International) need to be aware from the outset that the development of independent learning skills is a characteristic of Higher Education.

Although most students said that they feel welcome in England, some commented that more could be done to help International and EU students (the latter were included in the English survey) adjust to an English environment. The survey group wanted to learn more about English culture and to make English friends. $65 \%$ said that they would like to mix more with British students, with a similar percentage wanting to learn more about British culture. In keeping with wanting to gain experience of living away from home, $82 \%$ of respondents said that they would like more contact with students of other nationalities.

"I think students from England should associate with International students".

Given the general perception abroad that England is not welcoming to foreign students, it will be useful for colleges to review their induction and pastoral care arrangements for these cohorts.

The 2013 MEG survey results suggested that more attention was given by colleges to meeting the needs of International students than their EU counterparts. In 2018, this sense still prevails. EU students pay the same fee as English Home students but have social and language needs more akin to those of International students. They are still more likely to question value for money or the administrative arrangements surrounding their studies than their International 
counterparts. International students know that they pay higher fees than Home or EU students and they know that colleges do not wish to lose the fee income that they bring. English colleges must take care not to overlook the needs of EU students in this context.

Under current proposals post-Brexit, EU students studying in England will pay International fees and have no entitlement to English student loans. FE colleges must review their support arrangements for existing EU students if they want to ensure on-going positive feedback to these students' home countries and future recruitment from Europe.

In response to the survey findings, English colleges have implemented or further-refined a number of initiatives. These include organising sessions specifically for overseas learners on specific evenings. These are social events, but are also used to promote British values and help non-Home students to acclimatise to British culture. The sessions are largely promoted to new arrivals to the UK.

Colleges are also developing relationships with local communities sharing a cultural or religious background with their International students. This can then act as a bridge to the wider community. As an example, a college with significant numbers of Nigerian students on its Nautical Science course has developed a link with a local Nigerian Pastor. He has helped the college to organise celebrations such as those for Nigerian Independence day, including the provision of traditional Nigerian food. (The college supports these events financially.) Non-Nigerian students are welcome to take part in these celebrations, adding an international multi-cultural dimension to the experience of Home students. This is often complemented by international social programmes which involve both International and English students.

International students have also expressed a wish for greater attention to be paid to achieving an appropriate balance between International and Home students when setting up class and seminar groups and allocating places in halls of residence. The same principle can be extended to induction sessions at the start of the academic year. Many colleges hold sessions dedicated to International students, who are identified as a discrete group, separate from English students. However, opportunities to integrate these activities are often missed.

International students believe that an early start to integrating them with Home students will have benefits for all concerned. One successful example of this includes establishing a "buddy" system, giving International students a friendly face in their year group whilst at the same time offering the Home student an opportunity to broaden their own social experience.

One college is building on its existing partnerships with European colleges to build links which go beyond the strictly transactional.

"Students take part in a Trade Mission project where they work with students from across the EU trying to promote a local business abroad. We are hosting the Trade Mission next year which will involve $100 \mathrm{EU}$ students and approximately 50 of our HE students from various subject areas, taking part in joint activities." 
In this way international awareness becomes embedded in the curriculum, helping to break down barriers for International students as they adjust to a new country and a different culture.

Some colleges recognise the international culture already implicit in some courses. The Head of the specialist Nautical Science course commented that:

"Our learners are from the Global Maritime sector. Seafarers, in general, are truly multicultural. The sector is officer-based with a hierarchical structure. There is an inherent willingness in all of our learners to explore and experience other cultures: we merely facilitate this".

\section{Moraine Valley Community College}

56 International students (24\% of the total) from 10 largely HVET curriculum areas completed the survey. Based on these responses, International students report that they are generally satisfied with Moraine Valley Community College. Some of the key outcomes from this survey included the following:

What were your main reasons for studying in the United States?

- To enhance employability prospects

- To improve my English

- To gain some experience studying abroad

Why did you choose to study Higher Education at a Community College in United States?

- Lower fees compared to a university

- Higher level of support compared to a university

Why did you choose to study at Moraine Valley Community College?

- Friends or family studied at Moraine Valley

- Location

- Lower Fees

- Reputation of Moraine Valley

Over $87 \%$ of the International students who completed this survey responded that they felt welcome on campus, and $72 \%$ would recommend the college to friends.

"I have been here for almost 3 years. I improved myself a lot. I achieved my dreams at $M V C C$ "

"Everybody welcomes you. They provide support and adequate information as well as help.

$87 \%$ expressed a wish to mix more with US students and $69 \%$ wanted to learn more about American culture. A small majority of students (56\%) stated 
that the approach to learning in the US was different to that in their home countries but $70 \%$ were satisfied with both the range of options within their courses and the resources available in the college library.

Despite high satisfaction levels overall, only $36 \%$ considered that what they received in terms of education programmes and resources was equal to what they paid in fees and other costs. Many students took the opportunity to add comments at the end of this particular question, reflecting the strength of feeling surrounding the overall cost of their course, payment methods and limited opportunities to work in order to supplement income

"Allow international students to get on payment plans. The amount paid upfront is insane".

"I think MVCC has really good curriculum for studying, but it is too expensive paying tuition for International students. I still don't understand why should we pay 3 times tuition to compared with local students."

Several areas for improvement emerged from the survey results. These included revising the tuition fee structure to include a more flexible payment plan for International students, coupled with increased opportunities to secure scholarships. International students were also keen to increase the hours of paid work available on campus. Away from financial matters, International students revealed that they would like more opportunities to engage with local students, and more events and activities that enabled them to experience American culture.

Based on these results, the college's International Education Committee has already scheduled events to increase the engagement between International students and Domestic students in and outside of the classroom. It should be noted that the International Student Ambassador Club has its highest member participation in 2018-19, with 38 students in total: 26 students are International and 12 students are Domestic. Many of the latter joined the International Student Ambassador Club as a means of learning more about their non-US peers.

Other events that took place during International Education week included International Education Trivia in which students were able to answer Trivia questions related to international education using Kahoot. "Teas around the World" saw students dressed in traditional clothing serving tea from various countries. Guests at the event were given a copy of the International Cookbook produced by the students. International students also participated in sports activities such as ping pong and basketball as part of an activity aimed at sharing experiences of the Olympic Games.

Away from these social activities, International students and students who have participated in Study Abroad shared their experiences at an International Student Panel. Students from different cultures presented facts about their country and culture in a Poster Sessions Showcase. Finally, the college organised an International Education Week, involving collaboration from different departments across campus, including the Celebrating Diversity Task Force, the International Education Committee, the Global and Diversity Education Programme and the International Student Affairs department. 


\section{Holmesglen Institute}

A total of 334 International students (38\% of total) across eight HVET discipline areas completed the survey in 2017. Key findings included the following:

What were your main reasons for studying in Australia?

- Reputation for the standard of its HE programmes

- Gain experience living abroad

- Enhance employability prospects

- Safe country for International students

Enrolling in HE as a path to living permanently in Australia only ranked as the $7^{\text {th }}$ most important reason for studying in Australia. In contrast, when asked to rank their intentions upon graduation, seeking permanent residency ranked in the top three. However, consistent with the top three ranking of the importance of enhancing employability as a reason for studying in Australia, students also indicated their number one intention upon completion of their studies is to seek employment in Australia. The survey data reinforces the relevance of the Temporary Graduate (485) visa streams to International student choice of Australia as a HE destination.

There is also some similarity to responses by students at Moraine Valley and within the MEG colleges who ranked enhancing employability prospects and gaining experience studying abroad in their top three reasons for studying in America and England. Holmesglen students, however ranked 'improving English language' much lower ( $8^{\text {th }}$ most important) than at Moraine Valley. It is perhaps worth investigating if this is related to government and admission requirements regarding English language, and/or the mix of countries each provider currently targets as a source of overseas students.

As with both Moraine Valley and the MEG group, reference was made to teaching style, with $85 \%$ agreeing/strongly agreeing that the style of learning in Holmesglen was different to that which prevailed in their home countries. $41 \%$ of those who had reservations about their HE experience wanted to be provided with additional academic support - perhaps reflecting the situation found by MEG (above) in relation to contact time.

Why did you choose to study higher education at Holmesglen Institute?

- Lower fees compared to a university

- Offered preferred course of study

- Reputation of the Institute

- Higher level of support compared to a university.

In line with the findings at Moraine Valley and MEG, lower fees compared to a university ranked as the most important reason students selected Holmesglen as their HE provider. This was reinforced by the $71.6 \%$ of respondents who, amongst 
some comments that fees had been increasing, still expressed the view that the institute offered good value for money.

It should be noted that $53.4 \%$ of respondents had studied a vocational pathway programme either at Holmesglen or another provider. As previously stated, International fees tend to be lower in vocational programmes, as these programmes are generally mapped for transfer to a relevant degree. The overall cost of study to overseas students entering $\mathrm{HE}$ via a pathway programme is thus reduced.

Further analysis of the survey data is required to determine if there is a difference in the perception of value for money between pathway students to those who gain direct entry to undergraduate study.

Regardless, the survey data provides further evidence of the popularity of pathway entry and the importance of lower fees in provider choice. The impact of the Australian Government allowing overseas students to package two or more programmes on one student visa should not be underestimated.

91.3\% of the International students who completed this survey responded that they feel welcome in Australia. 78.9\% expressed a desire to mix more with students from different cultures and nationalities. $74.9 \%$ also wanted the opportunity to mix more with Australian students. This strength of feeling is reflected in the comments added to this section of the survey.

"Maybe our school could have more activities like a movie club or some other activities that can help students from other countries meet together".

"I believe that the best way to experience another culture is through food! A food fair where different cultures present their food would be awesome! "

Similar areas for improvement to those noted by Moraine Valley emerged. Students had strong feelings about fee levels and payment methods. In response, the Institute reviewed a number of procedures. These included increasing the number of fee payment instalments available for International students through a revised payment plan and increasing scholarship opportunities.

International students also wanted to have more input into teaching and learning, student administration, and life on campus (including mixing with Domestic students and those from other cultures). They wanted to do this by engaging their voice in academic governance, expanding International representation in the Student Association and increasing participation in focus groups.

The Institute has listened to these concerns and aims to find ways of empowering International students through a number of structural reforms. As part of that response, an Executive Director responsible for support and engagement across the Institute has been appointed, along with a Student Engagement Manager responsible for student experience initiatives across the Institute and a Student Engagement Manager with specific responsibility for the International student experience.

Holmesglen has also appointed International student ambassadors and representatives to faculty governance committees and the student association. They will provide feedback and make recommendations regarding teaching and 
learning, life on campus and social activities from an International student perspective. This includes support for an International student cricket team competing in a local district cricket league.

International students organise and lead study groups, mentored by academic staff. This complements a "degree buddy" system to support International students aiming to progress to a higher level vocational programme.

Finally, the Institute has joined a national pilot programme to enhance student engagement in decision-making and governance. Holmesglen is the only non-university provider to participate in this programme, alongside 10 Australian universities. Holmesglen will provide an International student as a member of the programme's Steering Committee and Reference Group.

\section{Discussion}

Our research began with the intention to explore the experience of International students studying $\mathrm{HE}$ in non-university institutions in three Anglophone countries. We considered work previously undertaken in this area, noting that it was predominantly from within the US Community College system, with lesser inputs from Australia and England.

Although this paper draws on that body of work, and confirms that many of the findings remain valid, it provides a fresh perspective by undertaking a comparative study across three different countries. That perspective continues to recognise the strength of the student voice, with perhaps surprising similarities across all three countries.

Based on the survey results, International students appear to enjoy their experience of studying for a higher level qualification in a college setting. They appreciate that they are taught by effective teachers who have relevant professional experience in their chosen field. Significantly, those teachers see themselves primarily as educationists, focusing on student learning rather than academic research. Staff and students consider that this enhances employability, which consistently emerges as a key motivation behind studying a vocational course overseas.

This reflects recent research elsewhere. The link between International student choice of HE provider and employability was discussed in ICEF Monitor (2019). This concluded that:

"Employability is now a top priority among international students when planning for study abroad

Many international students, especially those from developing economies, are keenly interested in studying in countries where there is a clear path toward employment after graduation and after that, even permanent residency."

The three colleges offer high levels of student support. This includes language support where needed but also more general pastoral support, including help with living away from home in a different country. 
"I think the academic staff is the reason why I stayed at Holmesglen. I can't thank most of my teachers enough for their encouragement".

Classes tend to be smaller in size than found in many universities, allowing greater individual interaction. Taken together these factors appear to outweigh any concerns about not studying in a traditional university.

However, International students are not uncritical of their experience. Many students reported concerns with issues of value for money, perceived or actual. Fees were seen to be high, especially when compared with the fee charged to Home students. This also extended to the inflexibility of payment methods and the bureaucracy which often surrounds visa and other regulations. Failure to address these issues could result in reduced International recruitment.

International students were also concerned at some of the obstacles which they felt made integration with Home students more difficult. They do not see themselves as a homogenous group, coming as they do from different social and cultural backgrounds. They had a strong desire to meet and form friendships with Home students both inside and outside the classroom. They did not want to learn or mix socially exclusively with people from their own countries. They felt more could be done to assist integration, for example by ensuring that tutorial groups were mixed and social activities were accessible to all. Changes such as these would be simple to devise, easy to deliver and inexpensive. In a comment reminiscent of Guyton 2017, one Chinese student pleaded:

"The class size is too small - which is a reason why I find it so hard to mix with the local students. Most of the local students in the class were friends (before they came to college) so when we do the group assignment then they already have premade group".

For institutions with large numbers of International students, failing to respond to these concerns could ultimately have an adverse effect on recruitment. This could in turn impact on the viability of courses and the experience of Home students. For all institutions participating in the survey, there are further steps which could be taken to enhance the international experience of local students without the need for travel.

As noted by Mellors-Bourne 2013 and Martin 2018, International students present a valuable resource. They bring global issues and experiences to Home students who may themselves be reluctant or unable to travel. Taking this approach may help to reduce the impression that International students are simply a source of income to the institution, illustrating instead that they form an important part of the experience for all students.

As was noted by Tran \& Dempsey 2017, recruiting International students calls for an institution-wide shift in management decision-making. Any initial effort will be more than rewarded with sustained recruitment and satisfied students. There is increasing competition for International students in all three countries represented in this research. Our survey results suggest that these students recognise the advantages offered by a college setting. However, in order to retain this recruitment advantage, non-university providers must address 
existing weaknesses through systemic change. We offer a means of promoting this through our Checklist (see Appendix).

\section{Conclusions}

This research paper sought to investigate a possible link between the personal experiences of International students studying in non-university contexts and successful practices by each institution regarding the integration of those these students. Our primary recommendation for institutions enrolling International students is to ensure a high level of support and integrative activities (Wu, Garza, \& Guzman, 2015).

In the course of the research, it became obvious that there were clear links between each Government's immigration policies (and within that their approach to International students) and the numbers of such students recruited each year. Reflecting our own findings, the three most recent national strategies for international recruitment, from France, Canada and the UK, all give prominence to increased student support measures, including social inclusion; help with housing; counselling, including support over mental health concerns, and, in the case of France and Canada, a significantly-more streamlined visa application process. As one respondent noted, colleges should not underestimate:

"The time it takes to adapt and transition into a new country including the challenges of securing accommodation and finding a job".

Our research output includes a Checklist of areas for discussion by senior management teams in colleges with International students. If such recruitment is a genuine strategic priority (as opposed to a particular interest on the part of a Departmental head, for example) then time must be given to planning how resources and activities are managed to deliver that strategy successfully. We consider that that the significance of this process is under-estimated, despite cumulative evidence from the voices of International students.

Whilst the higher policy issues identified may lie outside the remit of institutions, the good practice points identified in the Checklist will be of immediate use. They will help to inform decision making at institutional level and improve the International student experience.

Sharing information and experience across three countries has underlined what works and signposted the advantages of an inclusive approach to International students. This recognises not only the value added to them as individuals but also the benefits for Home students as they prepare for work in a global economy.

This three-way study may not only offer a useful comparator for the institutions concerned, but will also broaden the wider HE community's understanding of International students' views, given that the starting point was a different style of learning to that offered in a traditional university setting. 


\section{References}

Association of American Community Colleges. (2019). Fast Facts. Retrieved from https://bit.ly/2FFKbNI.

Conlon, G., Halterbeck, M., \& Hedges, S. (2019). The UK's revenues from International students post-graduation. Higher Education Policy Institute and Kaplan International Pathways, London, England.

Department for Education \& Department for International Trade. (2019). International Education Strategy: global potential, global growth. London, England.

Department of Home Affairs. (2018a). Retrieved from https://bit.ly/2RA88bH.

Department of Home Affairs. (2018b). Student visa and Temporary Graduate visa program report. Canberra. Australia.

Guyton, D. T. (2017). Adjusting to Community College as an International Student in Appalachia. Doctor of Philosophy (PhD) dissertation, Educational Foundations \& Leadership, Old Dominion University. doi: 10.25777/4kev-av73.

Higher Education Funding Council for England. (2017 and 2018). HEIFES 16 and HEIFES 17 FE data returns. Bristol, England.

Higher Education Statistics Agency. (2018). Where do HE students come from? Cheltenham, England.

House of Commons Home Affairs Committee. (2018). Immigration policy: basis for building consensus. Retrieved from https://bit.ly/3iDVGDT.

ICEF Monitor. (2018). Australia's international education exports grew by $22 \%$ in 2017. Retrieved from https://bit.ly/3c8P5Pq.

ICEF Monitor. (2019), The link between employment outcomes and recruiting. Retrieved from https://bit.ly/2FC9j8e.

Kumari, P. (2018). Staying Ahead: are International students going down under? For Policy Connect and the Higher Education Commission. London, England.

Leask, B., \& Carroll, J. (2013). Learning and Teaching Across Cultures. Good Practice Principles and Quick Guides. Melbourne: International Education Association of Australia.

Lee, J.J., \& Rice, C. (2007). Welcome to America? International student perceptions of discrimination. Higher Education, 53(3), 381.

Martin, F. (21 May 2018). "The Interpreter". The Lowy Institute. Melbourne, Australia.

Mellors-Bourne, R., Humphrey, C., Kemp, N., \& Woodfield, S. (2013). The Wider Benefits of International Education in the UK. Prepared by the Careers Research \& Advisory Centre (CRAC) Ltd for the Department for Business, Innovation and Skills. BIS Research Paper number 128. London. DBIS.

NAFSA. (2009). A Visa and Immigration Policy for the Brain-Circulation Era: Adjusting To What Happened in the World While we Were Making Other Plans. https:// bit.ly/3caQFQO.

NAFSA. (2019a). Welcoming International students and scholars. https://bit.ly/3If HOJg

NAFSA. (2019b). International student Economic Value tool. https://bit.ly/32DA0 C3.

Open Doors. (2019). Institute of International Education. USA. Retrieved from https:// bit.ly/3hDFVLG.

Redden, E. (13 November 2018). New international student enrolments continue to decline at U.S. universities. Retrieved from https://bit.ly/2FIlboP.

Smith, R., \& Khawaja, N. (2011). A review of the acculturation experiences of International students. International Journal of Intercultural Relations, 35(6), 699-713. 
TEQSA. (2018). Statistics report on TEQSA registered higher education providers 2018. Melbourne. Australia.

Tran, L, T, \& Dempsey, K. (2017). (Eds.) Internationalisation in Vocational Education and Training: Transnational perspectives. Dordrecht, Springer.

UK Council for International Student Affairs. (2017). Briefing on International students. www.ukcisa.org.uk/briefing-on-students.

Vafors Fritz, M., Chin, D. \& DeMarinis, V. (2008). Stressors, anxiety, acculturation and adjustment among International, and North American students. International Journal of Intercultural Relations, 32(3), 244-259.

Wu, H.-P., Garza, E., \& Guzman, N. (2015). International student's challenge and adjustment to college. Education Research International, 1-9. doi: 10.1155/ 2015/202753

Yeh, C.J., \& Inose, M. (2010). International students' reported English fluency, social support satisfaction, and social connectedness as predictors of acculturative stress. Counselling Psychology Quarterly, 16(1), 15-28, doi: 10.1080/095150703100 0114058. 


\section{Appendix}

\section{International student recruitment: Checklist for senior college managers}

\section{How does the recruitment of International students fit with the strategic priorities of your college?}

- Are you aware of the current visas and immigration service procedures surrounding the admission of International students to the UK/Australia/ USA? Is this reflected in the information given to potential applicants?

- Does your college have the systems and procedures required to satisfy compliance with national arrangements such as the UK's Highly Trusted Status? How do you monitor this?

- Have you considered the level and sensitivity of the fee charged to International students? Would student numbers be affected by a change in fees?

- Are International students a significant part of the student community? If so have you considered what different or additional support needs they may have? Can such support be provided on an individual basis?

- Do you provide appropriate facilities and support for your International students e.g. assistance with housing, dedicated pastoral or language support?

- How does your college support and educate staff, such that they understand the cultural sensitivities that they will encounter when dealing with International students?

- Does the level of academic support offered help both International and Home students to succeed?

- In addition to the high academic standards and quality of learning experience that your International students expect, have you provided opportunities for them to gain a wider knowledge or experience of life in the UK/Australia/USA?

- Are you fully informed about regional internationalisation programmes? For example, in Europe, EU programmes such as Erasmus and Jean Monet?

- Is the blend of nationalities in your HE classes as balanced as it can be? Does it enable International students to mix with Home students and build networks and friendships outside the classroom?

- How are you using your International students to broaden your curriculum with a more global context? 